\title{
revestimientos bituminosos de las obras hidrăulicas
}

\author{
GEORGES VIÉ, ingeniero de minas
}

Se trata aquí del empleo adecuado de los betunes en la solución de numerosos problemas que presentan algunas obras hidráulicas, tales como los canales de abastecimiento, protección de muelles, diques, etc.

Debido a su gran flexibilidad e impermeabilidad, permiten la construcción de obras capaces de resistir erosiones y choques, sin necesidad de hacer juntas. Además, conviene tener en cuenta su facilidad y rapidez de colocación, todo lo cual favorece y generaliza cada vez más su empleo.

Los betunes poseen una aptitud excepcional para resolver numerosos problemas hidráulicos.

De gran flexibilidad e impermeabilidad, se comportan como materiales plásticos o elásticos según las condiciones de temperatura y carga a que están sometidos. Permiten la construcción sin juntas de obras resistentes a la erosión y a los choques, y su flexibilidad les da la facultad de adaptarse a los asientos y socavaciones de su soporte.

Escollera del Adour: Colocación de protección rocosa

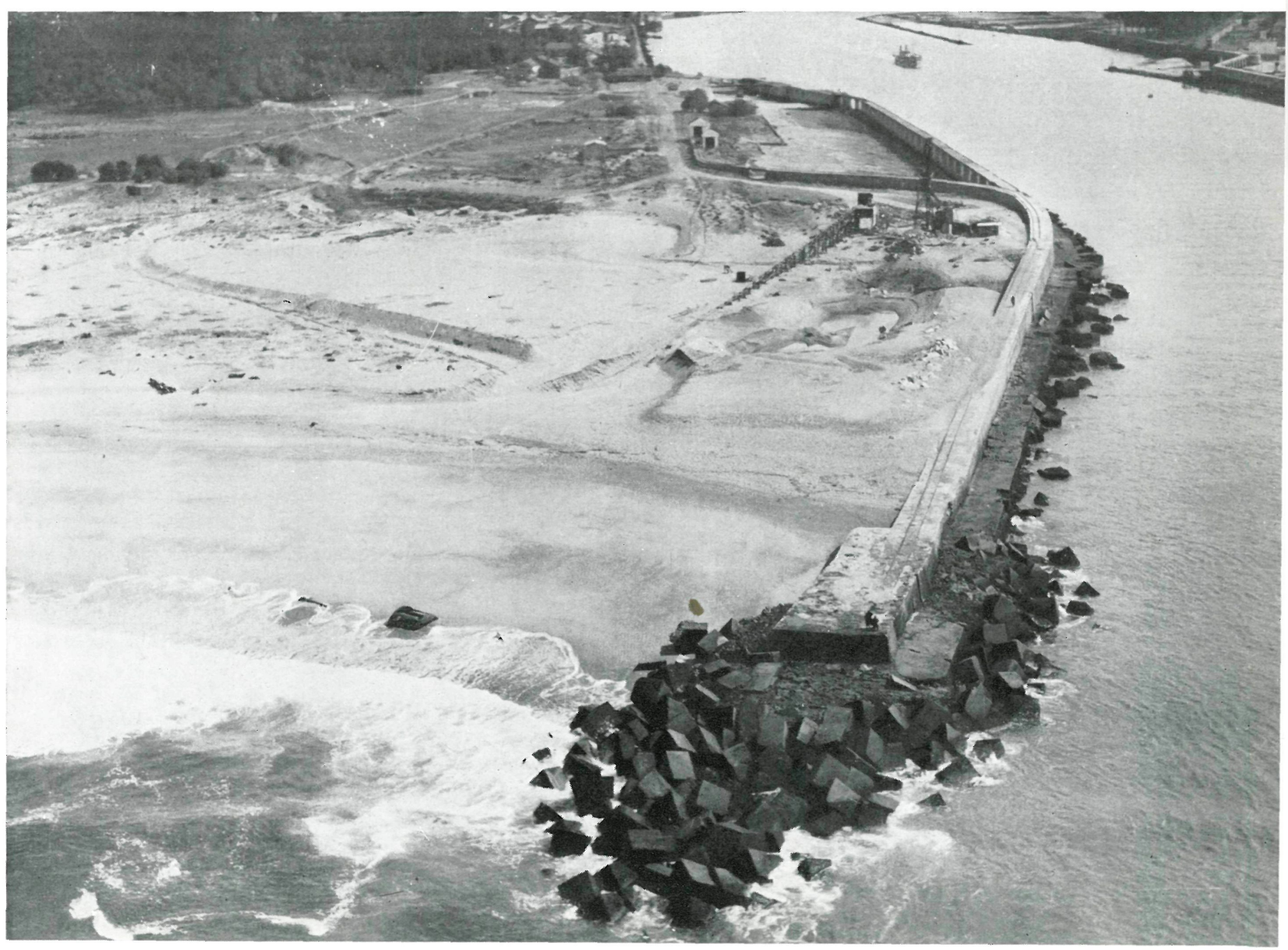




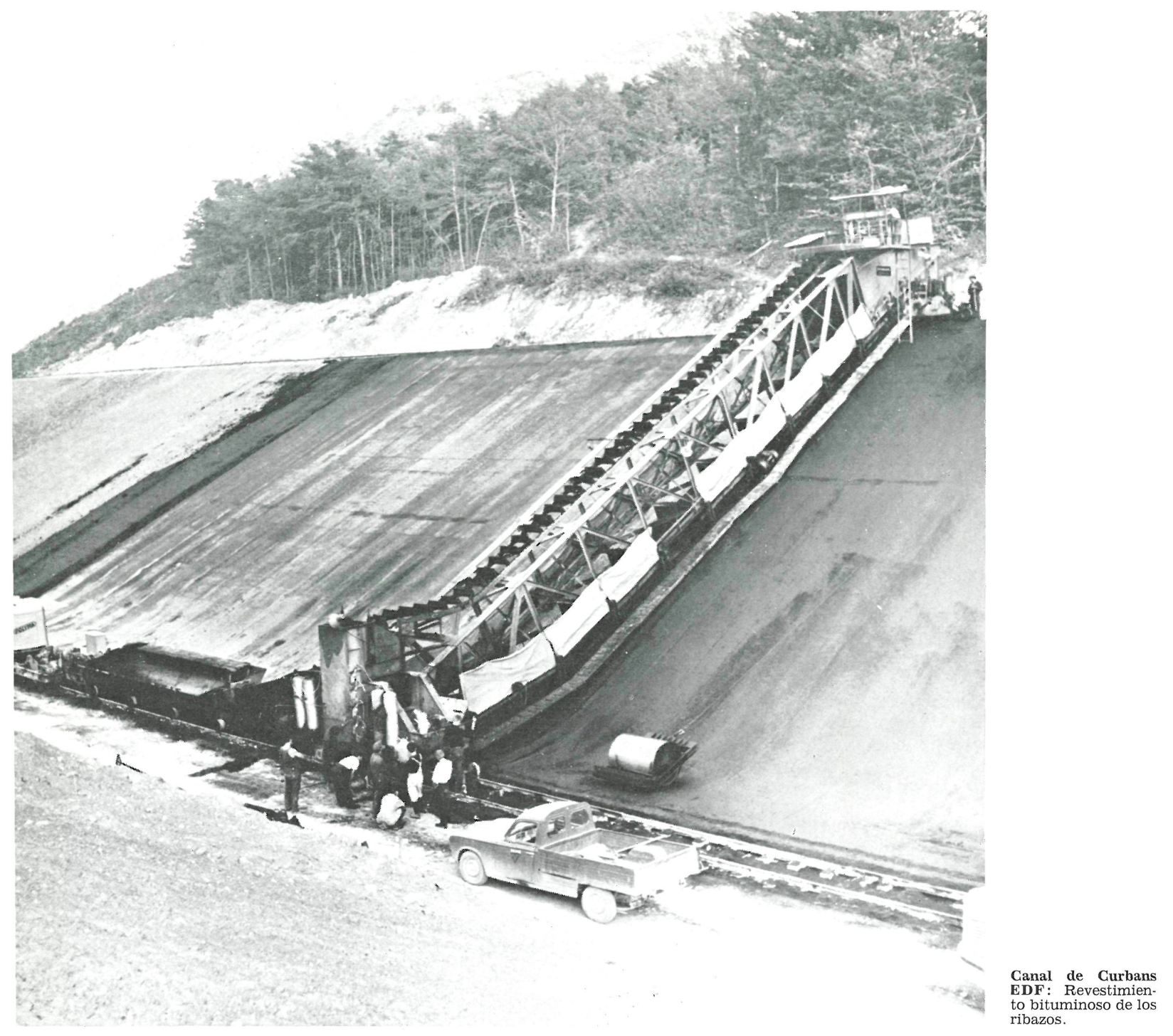

Por último, hay que tener en cuenta su rapidez de colocación. Para los betunes puros, ésta se efectúa por simple enfriamiento, lo que hace fáciles el mantenimiento y la reparación de las estructuras bituminosas.

Los problemas de subpresiones, de sellado y de fluencia a temperaturas elevadas pueden, la mayor parte de las veces, resolverse por un estudio de laboratorio y una elección juiciosa de las técnicas de puesta en obra.

Según los fines buscados, las técnicas de empleo pueden ser:

El simple derramamiento de betún puro fundido para la realización de lechos de apresto, de encolado o de sellado, o de membranas estancas enterradas bajo una protección de terraplén.

El mástique bituminoso, compuesto en principio por arena, filler y una proporción de betún tal que la mezcla fluya fácilmente alrededor de los $180^{\circ} \mathrm{C}$ en un armazón estable de materiales gruesos no muy juntos.

Esta técnica es aconsejable en construcciones de grandes masas y en las obras sumergidas.

El hormigón bituminoso, así como los materiales asimilados al betún puro, adaptados a las técnicas hidráulicas, empleados para trabajos pesados en el mar, o para cámaras estancas o de una permeabilidad determinada. 
Los elementos prefabricados obtenidos por asociación de una de las estructuras precedentes a una armadura apropiada, para trabajos en el agua o al aire libre.

Finalmente, las inyecciones de betún puro fundido, emulsiones de betún, o mezclas especiales, con el objeto de realizar taponamientos o estancamientos de recalces.

En la construcción de saltos de agua con grandes costos, la construcción de los canales de abastecimiento representa una gran parte de los gastos.

El revestimiento de algunos de éstos ha sido realizado en hormigón de cemento, pero éste soporta mal las deformaciones de su soporte; de aquí las resquebrajaduras y las pérdidas que agravan la complicación de la obra.

Tres grandes tipos se emplean en los revestimientos bituminosos:

1 Materiales recubiertos filtrantes, que se oponen a la polución de las otras capas por los elementos finos del soporte.

2 Recubrimientos de drenaje, muy recomendados si hay riesgo de subpresiones.

3 Recubrimientos estancos, que constituyen los hormigones bituminosos de alta calidad.

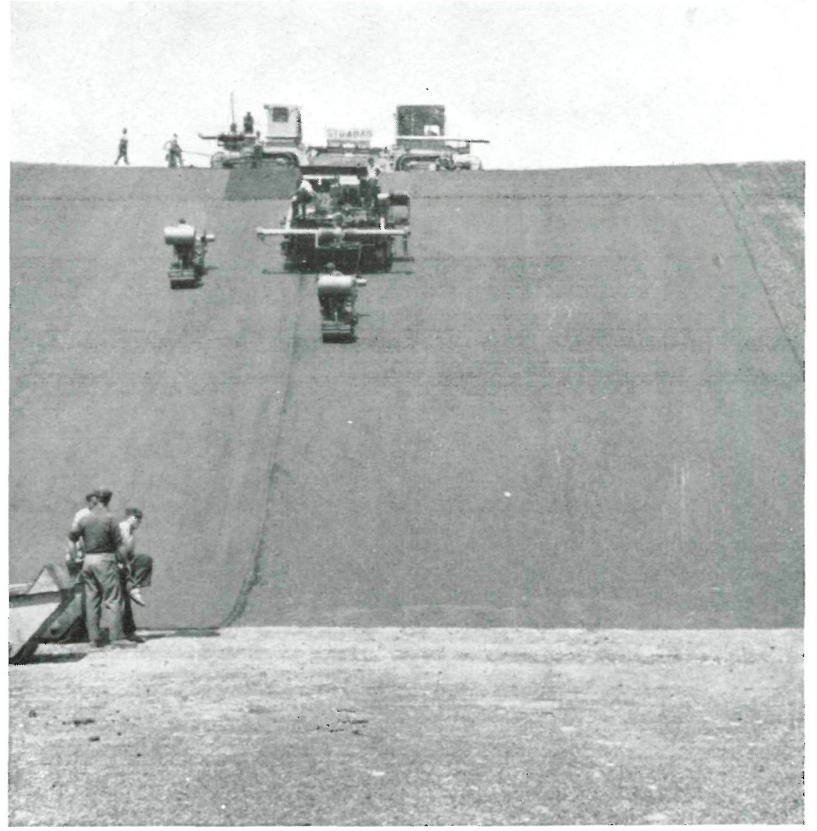

Dársena de Vianden (Luxemburgo): Revestimiento de los ribazos.

Canal. Depósito Sena: Revestimiento bituminoso de los ribazos.

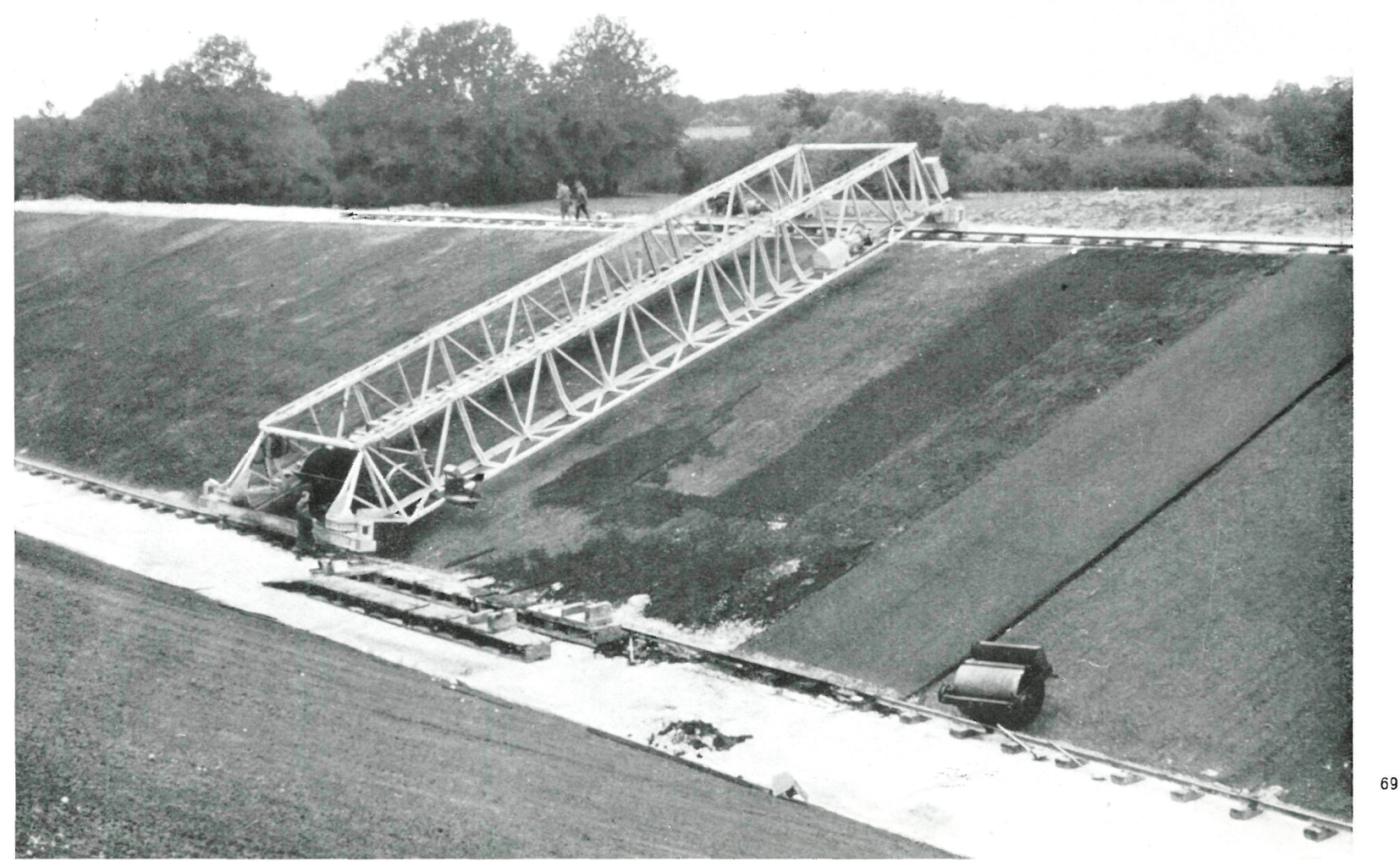




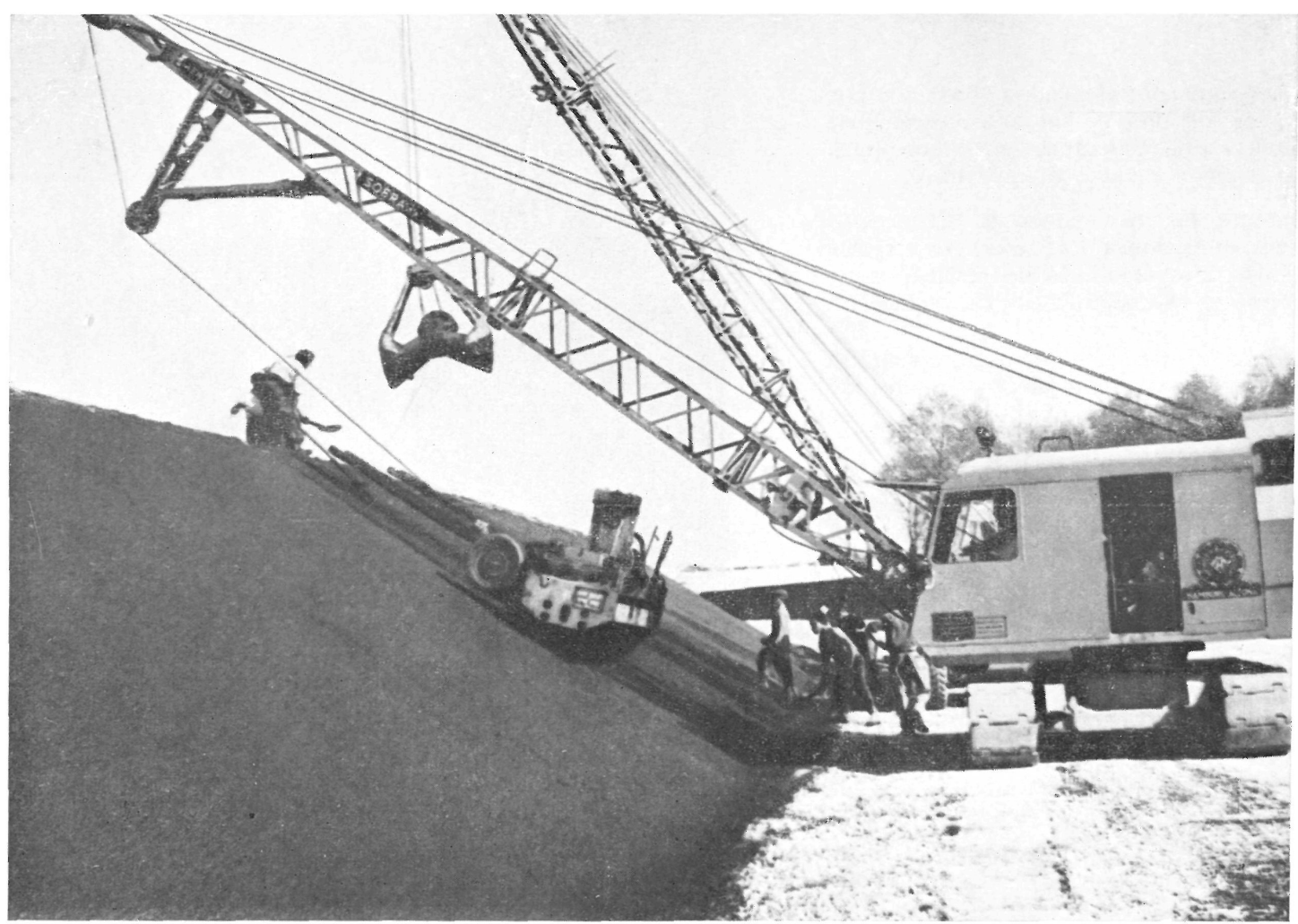

Canal del Marne, ción de Rin: DerivaFrançois.

Los saltos de agua en los que ha trabajado recientemente Electricité de France, sobre el curso del Durance, proporcionan algunos ejemplos interesantes.

El canal de abastecimiento del salto de Curbans atraviesa en el borde del acantilado del Lias una zona de derrubios y yesos muy sensibles al agua.

En la casi totalidad de su trazado, esta obra se halla situada en terraplenes formados con préstamos tomados del lecho aluvial del Durance y de escombros y desmontes procedentes de la apertura de las galerías.

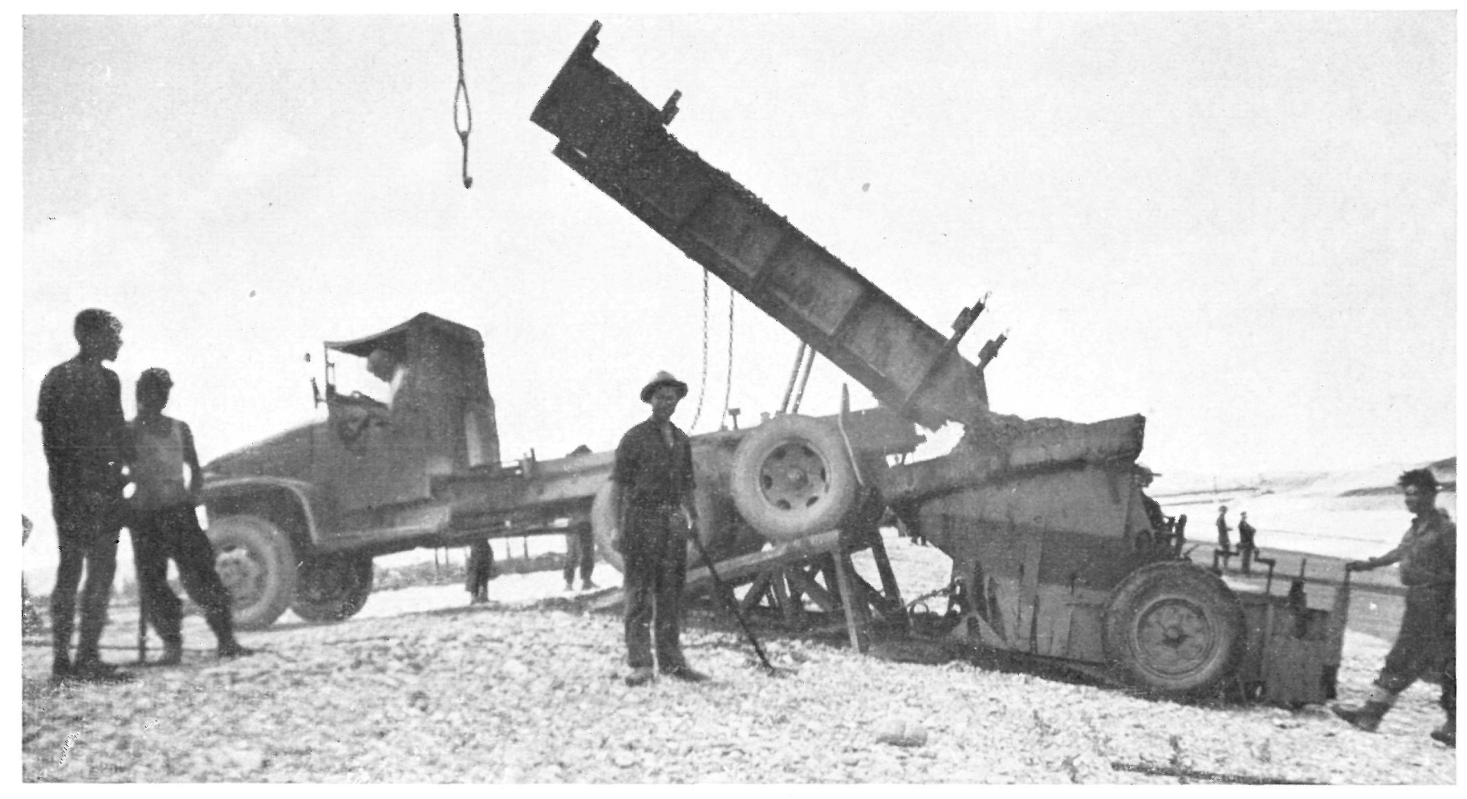

Canal de derivación
del salto de Donzè. re-Mondragon sobre el Ródano. 
La diversidad y falta de homogeneidad de estos materiales y la preocupación de realizar un revestimiento estanco han hecho adoptar recubrimientos bituminosos estancos, aplicados en una o varias capas, correspondientes a los tres grandes tipos citados anteriormente, en función de la naturaleza de los ribazos.

$\mathrm{Al}$ atravesar las zonas de escombros y de aluviones muy finos se han echado sucesivamente: una capa de drenaje, de $0,10 \mathrm{~m}$ de espesor, y dos capas estancas, cada una de 0,045 m. Para cada una de ellas, los recubrimientos empleados presentaban la composición granulométrica siguiente:

\begin{tabular}{|c|c|c|c|c|}
\hline \multirow[b]{2}{*}{ Gravillas trituradas $7 / 15$} & \multirow{2}{*}{$\begin{array}{c}\begin{array}{c}\text { Capa } \\
\text { filtrante }\end{array} \\
30 \%\end{array}$} & \multirow{2}{*}{$\begin{array}{c}\begin{array}{c}\text { Capa } \\
\text { de drenaje }\end{array} \\
40 \%\end{array}$} & \multicolumn{2}{|c|}{$\begin{array}{c}\text { Hormigón bituminoso } \\
\text { estanco }\end{array}$} \\
\hline & & & $30 \%$ & (en peso) \\
\hline Gravillas trituradas $3 / 7$ & $20 \%$ & $35 \%$ & $20 \%$ & $»$ \\
\hline Arena de machaqueo $0 / 3$ & $50 \%$ & $25 \%$ & $16 \%$ & $»$ \\
\hline Arena molida $0 / 2$ & - & - & $24 \%$ & $»$ \\
\hline Filler calcáreo & - & - & $18 \%$ & $»$ \\
\hline Betún $60 / 70$ & 4,2 & 9,2 & 8,3 & (partes en \\
\hline
\end{tabular}

Los recubrimientos fueron preparados en una máquina discontinua a razón de $150 \mathrm{t} / \mathrm{h}$ y su colocación se efectuó por medio de una máquina con derramamiento longitudinal, dotada de un dispositivo de vibroacabado análogo al de las máquinas repartidoras que se emplean en carreteras, y que aseguraba, al mismo tiempo, el revestimiento de una parte de la pantalla de protección contra filtraciones. Dos rodillos lisos aseguraban la compactación.

El canal de abastecimiento del salto de Oraison es de sección trapezoidal con ribazos horizontales sobre la orilla izquierda del Durance. Su longitud total es de $21.500 \mathrm{~m}$, de los cuales 2.770 están cubiertos. EI revestimiento estanco de este canal consta de una solera de drenaje en los tramos donde los materiales de nivelación del terreno no ofrecen una permeabilidad suficiente.

Las superficies revestidas representan un área de $980.000 \mathrm{~m}^{2}$; de ellos 290.000 en hormigón bituminoso. A estas cifras es necesario añadir la obra de desaguie y recuperación, con $3.000 \mathrm{~m}$ de canal, de los que 1.700 están revestidos de hormigón bituminoso, lo cual supone una superficie suplementaria de $95.000 \mathrm{~m}^{2}$.

Los materiales de recubrimiento «abiertos» presentaban, en capas de 0,06 $\mathrm{m}$ de espesor, la composición siguiente:

$\begin{array}{lrc}\text { Gravilla } 4 / 15 & 73 \% & \text { (en peso) } \\ \text { Arena } 0 / 4 & 25 \% & " \\ \text { Filler calcáreo } & 2 \% & \text { " } \\ \text { Betún } 60 / 70 & 7,8 & \text { (partes en \% de áridos) }\end{array}$

La capa de hormigón bituminoso estanco (0,05 $\mathrm{m}$ de espesor) comprendía:

\begin{tabular}{|c|c|c|}
\hline Gravilla de machaqueo $4 / 15$ & $15 \%$ & (en peso) \\
\hline Gravilla rodada $4 / 8$ & $28 \%$ & $"$ \\
\hline Arena de machaqueo $0 / 4$ & $35 \%$ & $》$ \\
\hline Arena rodada $0 / 1$ & $15 \%$ & » \\
\hline Filler calcáreo & $7 \%$ & $»$ \\
\hline Betún $60 / 70$ & 7,8 & (partes en \% de áridos) \\
\hline
\end{tabular}

La colocación se hizo por bandas contiguas, con ayuda de un terminador arrastrado por una cabria; el apisonamiento se efectuó con rodillos lisos movidos con cabria.

En lo que respecta a la obra de abastecimiento del salto de Vinon sobre el Verdon, se consideran tres tramos subterráneos, alternando con el canal a cielo abierto de Malaurie $(3.100 \mathrm{~m})$ y el de Boutre $(900 \mathrm{~m})$, ambos totalmente revestidos, representando en conjunto $100.000 \mathrm{~m}^{2}$ de hormigón bituminoso.

Estos canales tienen: $8 \mathrm{~m}$ de anchura al ras del suelo, una profundidad de $4 \mathrm{~m}$ y una pendiente de ribazos de $2 / 1$

El caudal puede alcanzar los $55 \mathrm{~m}^{3} /$ segundo.

El trazado era, en su mayor parte, de terraplén. Las deformaciones apreciables estaban previstas; de aquí que la elección del tipo de revestimiento se adaptara a los asientos eventuales.

Se colocaron una capa de drenaje, de $0,08 \mathrm{~m}$ de espesor, y dos capas estancas, de 0,035 $\mathrm{m}$ cada una, en el canal de Boutre, y de $0,045 \mathrm{~m}$, en el de Malaurie. 
Es interesante comparar las granulometrías en los casos precedentes (los áridos proceden de una cantera de balasto de Durance):

\section{Revestimientos de drenaje}

Elementos rodados $7 / 15$

$48 \%$ (en peso)

Elementos de machaqueo $3 / 7$

Elementos de machaqueo $0 / 3$

Filler calcáreo

Betún 60/70

$$
2 \%
$$

3,8 (partes en \% de áridos)

\section{Revestimientos estancos}

\begin{tabular}{|c|c|c|}
\hline Elementos rodados $7 / 15$ & $34 \%$ & (en peso) \\
\hline Elementos de machaqueo $3 / 7$ & $15 \%$ & $\gg$ \\
\hline Arena rodada $0 / 3$ & $10 \%$ & » \\
\hline Arena de machaqueo $0 / 3$ & $35 \%$ & $»$ \\
\hline Filler calcáreo & $6 \%$ & $»$ \\
\hline Betún 60/70 & 7,8 & (partes en $\%$ de áridos) \\
\hline
\end{tabular}

Para el tramo de Malaurie el método de trabajo fue un vertido longitudinal continuo a lo largo del ribazo, mientras que para el tramo de Boutre se hizo el vertido por bandas transversales contiguas.

Aguas abajo (parte terminal del curso artificial del Durance), la obra EDF representa $14 \mathrm{~km}$ de longitud entre la toma de la central de Salon y la central de Saint Chamas, la cual vierte directamente en l'Etang de Berre.

El canal Salon-Saint Chamas mide $8,6 \mathrm{~m}$ de anchura al ras del suelo; la pendiente del talud es de 2/1, que pasa a 3/2 al atravesar una zona rocosa, y con una inclinación de la solera de 0,15 $\mathrm{m}$ /kilómetro.

Los materiales bituminosos aseguran el revestimiento del canal en $9 \mathrm{~km}$. Este revestimiento estanco es de hormigón bituminoso colocado sobre una capa de drenaje formada, por un lado, sobre la solera, a base de materiales aluviales compactados; y por otro, sobre los ribazos, por un hormigón aireado. Fue esparcida sobre la superficie de hormigón descarnado una capa de agarre formada por una emulsión catiónica.

El hormigón bituminoso comprende dos capas, de 0,05 $\mathrm{m}$ de espesor cada una, sobre la solera; y otras dos capas, de $0,035 \mathrm{~m}$ cada una, sobre los ribazos. Ha sido fabricado por dos máquinas discontinuas automáticas, situadas: una cerca de Salon (55.000 $t$ de revestimiento) y la otra cerca de Saint Chamas (35.000 t), con las siguientes dosificaciones:

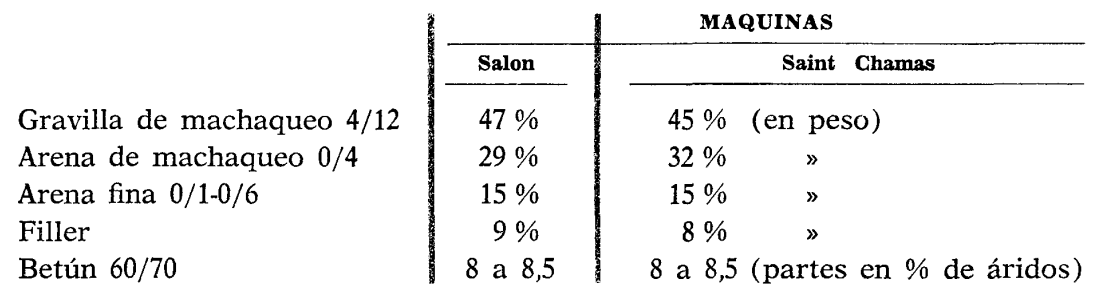

La técnica de puesta en obra sobre los ribazos ha consistido en trabajar a base de bandas continuas con un terminador que operaba normalmente al eje del canal, en el interior de un marco formado por dos vigas capaces de desplazarse sobre raíles colocados, uno, sobre la solera, y otro, sobre el ribazo.

El aprovisionamiento del terminador estaba asegurado por camiones que circulaban por el fondo del canal, donde el revestimiento había sido efectuado con un material de carretera de tipo tradicional. La compactación estaba realizada por dos rodillos lisos. Se vuelve a encontrar, por tanto, aplicado aquí el método considerado como más clásico.

Para los canales de derivación del Ródano (saltos de Donzère, Montélimar, Baix-Logis Neuf, Beauchastel, Bourg les Valence, realizados por la Compagnie Nationale du Rhône), los ribazos en terraplén o en desmonte están formados por los aluviones del Ródano, de composición más bien grosera, con abundancia de cantos rodados y una relativa escasez de arena fina. La pendiente de los taludes interiores es de 3/1.

Estos taludes, al nivel del agua, se hallan sometidos a los efectos de olas de $1 \mathrm{~m}$ de altura, provocadas por la violencia del mistral y por el paso de chalanas automotoras.

La protección se ha hecho por medio de una capa de revestimientos bituminosos, con una flexibilidad suficiente para admitir los asientos eventuales de los ribazos, formados en terraplén. 
Este revestimiento se limita a las proximidades del nivel medio del agua. Sin embargo, el revestimiento ha sido concebido para dejar una cierta permeabilidad y evitar las subpresiones donde eran susceptibles de manifestarse cambios bastante rápidos de nivel.

Esta permeabilidad prevista inicialmente, del orden de $10^{-1} \mathrm{~cm} / \mathrm{s}$ en el canal de Donzère, fue modificada en obras más recientes, en las que se ha llevado a $10^{-3} \mathrm{~cm} / \mathrm{s}$. Las derivaciones de Donzère y Montélimar han sido provistas de un revestimiento formado así:

$\begin{aligned} & \text { Caliza triturada } \\ & 15 / 30\end{aligned}$
$\begin{aligned} & \text { Caliza triturada } \\ & 5 / 15\end{aligned}$
$\begin{aligned} & \text { Arena de (en peso) } \\ & \text { machaqueo 0/3 }\end{aligned}$
$\begin{aligned} & \text { Filler calcáreo } \\ & \text { Betún 60/70 }\end{aligned}$
$\begin{aligned} & 5,5 \% \\ & 5\end{aligned} \quad \begin{aligned} & \text { (partes en \% } \\ & \text { de áridos) }\end{aligned}$

En Bourg les Valence, la composición se ha modificado:

$\begin{array}{lc}\text { Gravilla } 8 / 15 & 48,5 \% \text { (en peso) } \\ \text { Arena de } & \\ \text { machaqueo 0/8 } & 48,5 \% \quad \text { \% } \\ \text { Filler calcáreo } & 3 \%{ }^{3} \% \\ \text { Betún 60/70 } & \begin{array}{l}5,5 \text { (partes en \% } \\ \text { de áridos) }\end{array}\end{array}$

En los Alpes de Grenoble, la instalación de Saint Georges de Commiers comprende las dos centrales EDF de Saint Georges y de Champ II, que trabajan en serie y están unidas por un canal, en el cual hay un tramo de $22.000 \mathrm{~m}^{2}$ revestido con hormigón bituminoso.

Este tramo, totalmente realizado en terraplén con materiales aluviales, mide $6,70 \mathrm{~m}$ de anchura de solera, $12 \mathrm{~m}$ de extensión de muros laterales y una pendiente para dichos muros laterales de $2 / 1$.

La gran permeabilidad de los aluviones, que forman por sí mismos un excelente drenaje, ha permitido realizar directamente, sin capa porosa intermedia, el revestimiento bituminoso estanco, formado por dos capas de 0,05 m de espesor cada una, con juntas encontradas.

El hormigón bituminoso comprende un $34 \%$ de materiales calizos:

\begin{tabular}{|c|c|c|}
\hline De machaqueo $8 / 10$ & \multicolumn{2}{|c|}{$32,5 \%$ (en peso) } \\
\hline De machaqueo 4/6 & $18,5 \%$ & $»$ \\
\hline Arena rodada $0 / 5$ & $40 \%$ & » \\
\hline Filler & $9 \%$ & $»$ \\
\hline Betún 60/70 & 7,4 ( & $\begin{array}{l}\text { s en } \% \\
\text { dos) }\end{array}$ \\
\hline
\end{tabular}

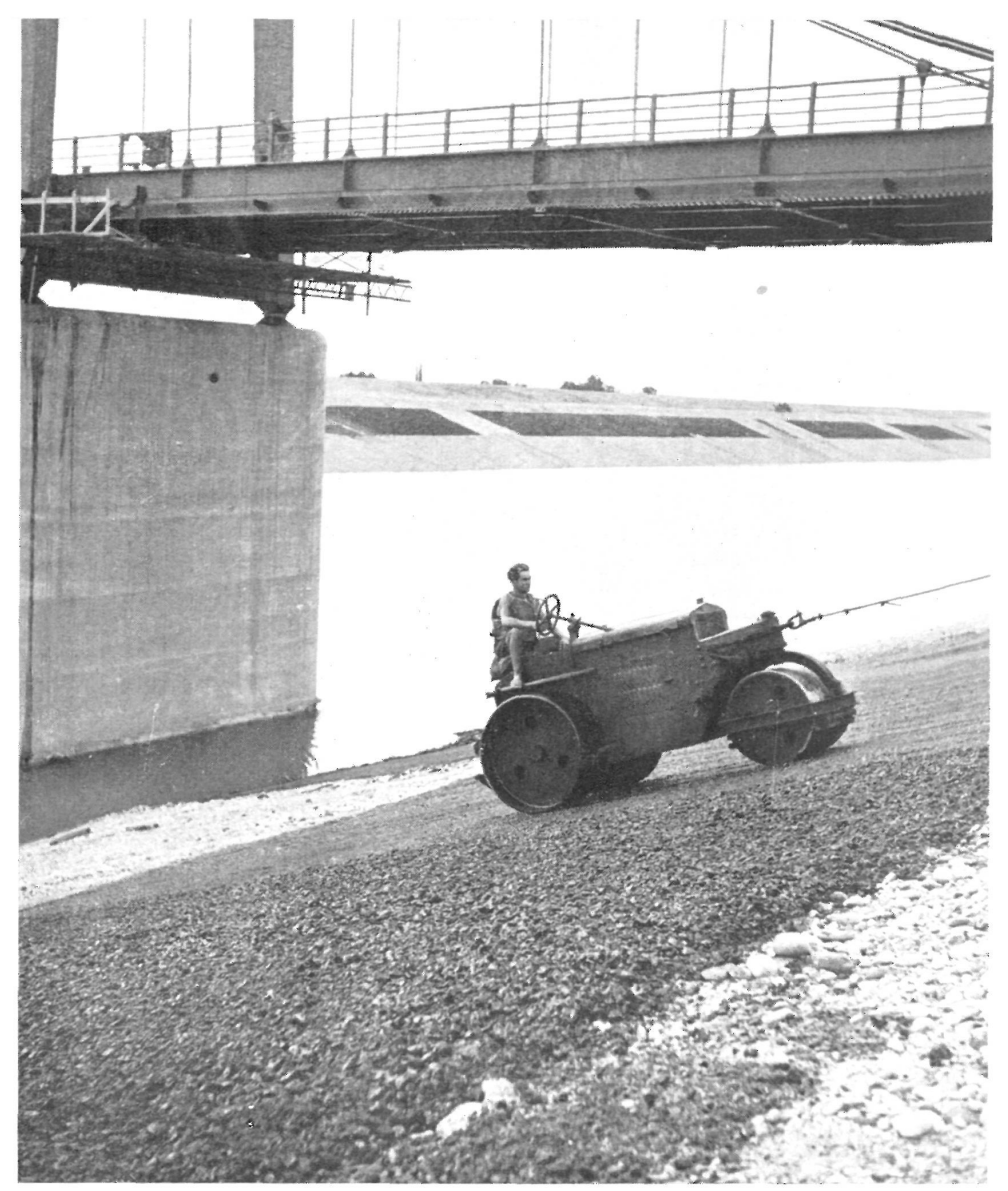

Canal de abastecimiento Donzère: Apisonamiento del revestimiento bituminoso.

Revestimientos bituminosos de los ribazos del canal de Gerstheim (EDF Rin).

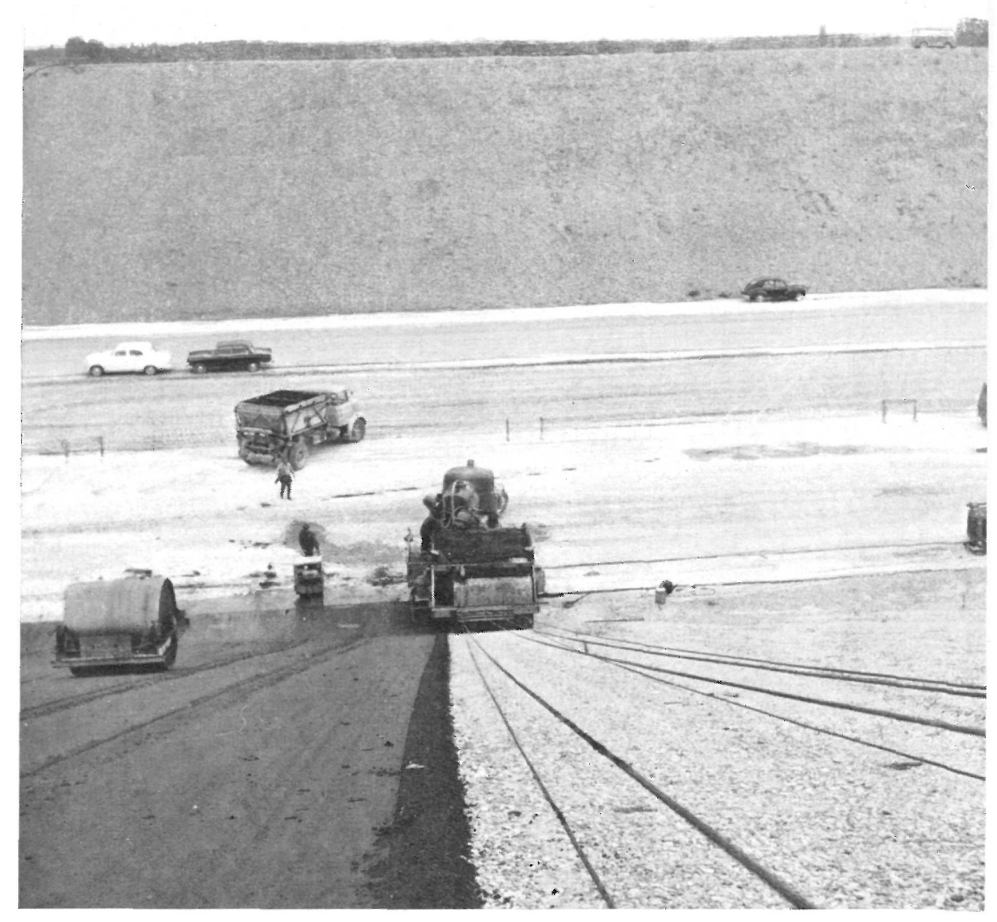




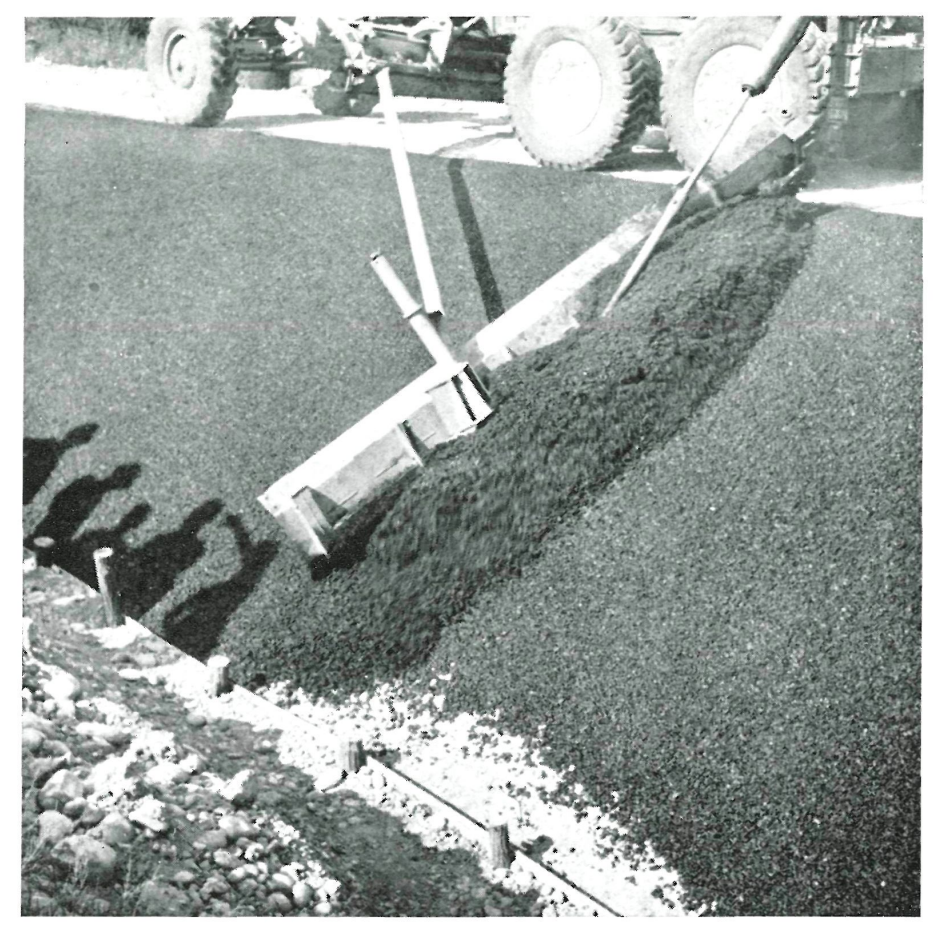

Canal de Huningue: Colocación de revestimientos bituminosos.

Antes de colocar el revestimiento, y para garantizar una mejor cohesión de la superficie del terreno, alisada y compactada, se hizo una impregnación a base de una emulsión ácida y a razón de $1 \mathrm{~kg} / \mathrm{m}^{2}$.

El hormigón bituminoso fue fabricado en una máquina de régimen discontinuo, a razón de $40 \mathrm{t} /$ hora.

Su colocación sobre el ribazo se hizo por medio de una máquina repartidora compuesta por dos vigas normales al eje del canal, de longitud regulable y con una separación de $5 \mathrm{~m}$, sobre las que circulaba una tolva que distribuía el revestimiento, por gravedad, sobre el talud.

El desplazamiento del conjunto se realizaba, paralelamente al eje del canal, sobre raíles longitudinales, uno colocado sobre la solera y otro sobre la berma.

Un Télépactor (dos rodillos de 1,3 t cada uno) aseguraba la compactación del hormigón bituminoso, y los rendimientos obtenidos en condiciones normales alcanzaron un valor de $1.500 \mathrm{~m}^{2} /$ día, para cada capa.

El revestimiento de la solera fue ejecutado con material de carretera tradicional.

Aunque el revestimiento fue de muy buena calidad, se llevó un control de laboratorio sobre muestras fabricadas in situ.

Para la compacidad, la media de los resultados fue del $96,5 \%$, y para la permeabilidad, entre $5 \times 10^{-7}$ y $1 \times 10^{-7} \mathrm{~cm} / \mathrm{s}$, también tanto sobre el revestimiento corriente como sobre las juntas.
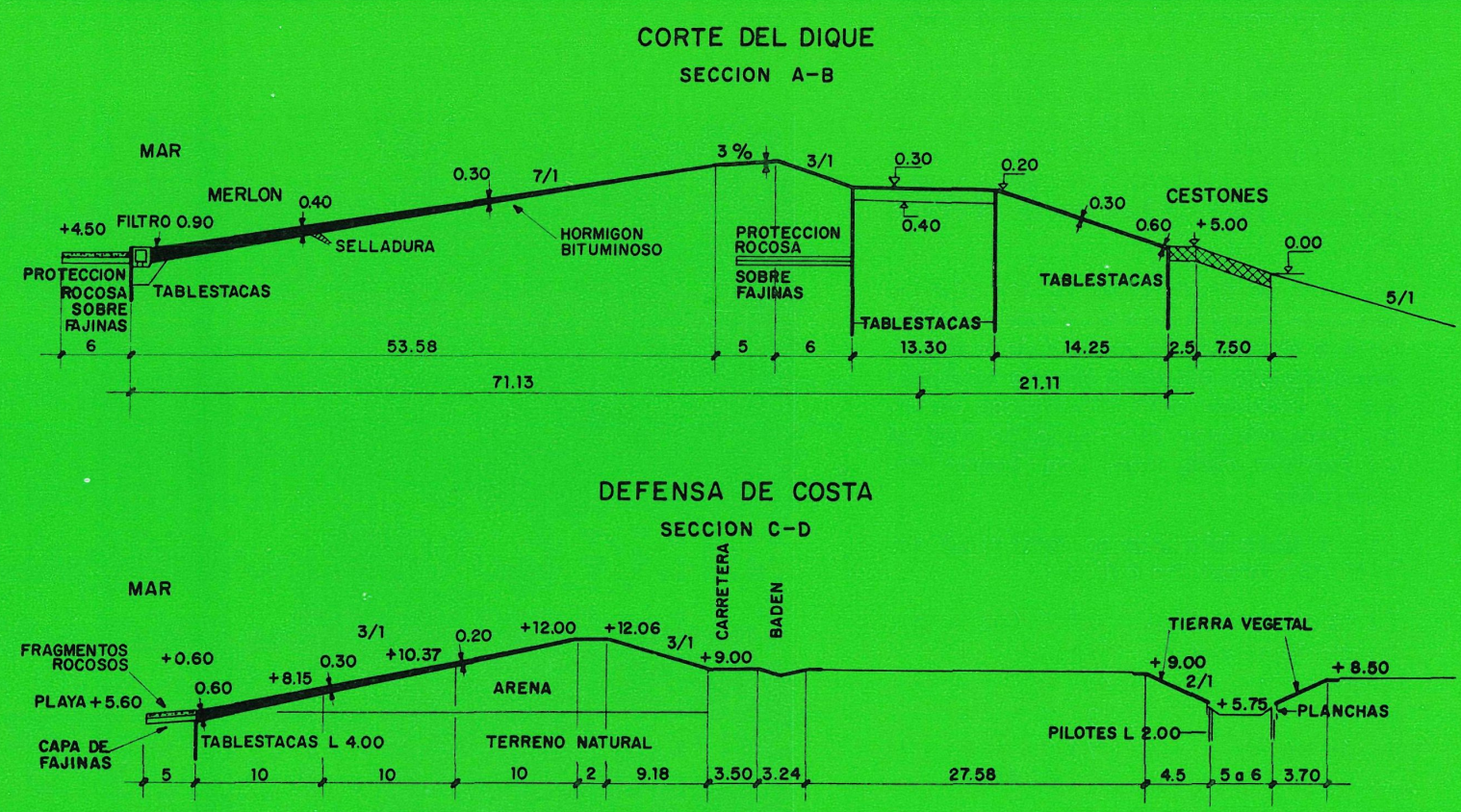
Mástique bituminoso: Trata miento de una protección de del Sena cerca de Honfleur.

Mástique bituminoso: Penetración del mástique.

Otro ejemplo de empleo de revestimientos bituminosos en obras hi. dráulicas viene dado por el salto de EDF de Gerstheim, sobre el Rin, un poco más arriba de Estrasburgo.

Esta instalación, la sép. tima aguas abajo de Bale, comprende un canal de abastecimiento de $5.500 \mathrm{~m}$, dividido en un brazo navegable, de $540 \mathrm{~m}$ de longitud, y un canal, de traída de aguas, de $930 \mathrm{~m}$, incluyendo la restitución de aguas al Rin.

El apartadero superior y el canal de derivación hacia la central han sido revestidos, en su totalidad, con hormigón bituminoso $\left(90.330 \mathrm{~m}^{2}\right.$, con $23.100 \mathrm{t}$ de revestimiento).

Las dos obras son de sección trapezoidal, de $52.5 \mathrm{~m}$ de anchura en su altura máxima para el canal de derivación y 96,25 m para el apartadero río arriba, con los taludes de las orillas inclinados a 2,5/1.

La parte superior y los taludes están recubiertos por una capa de

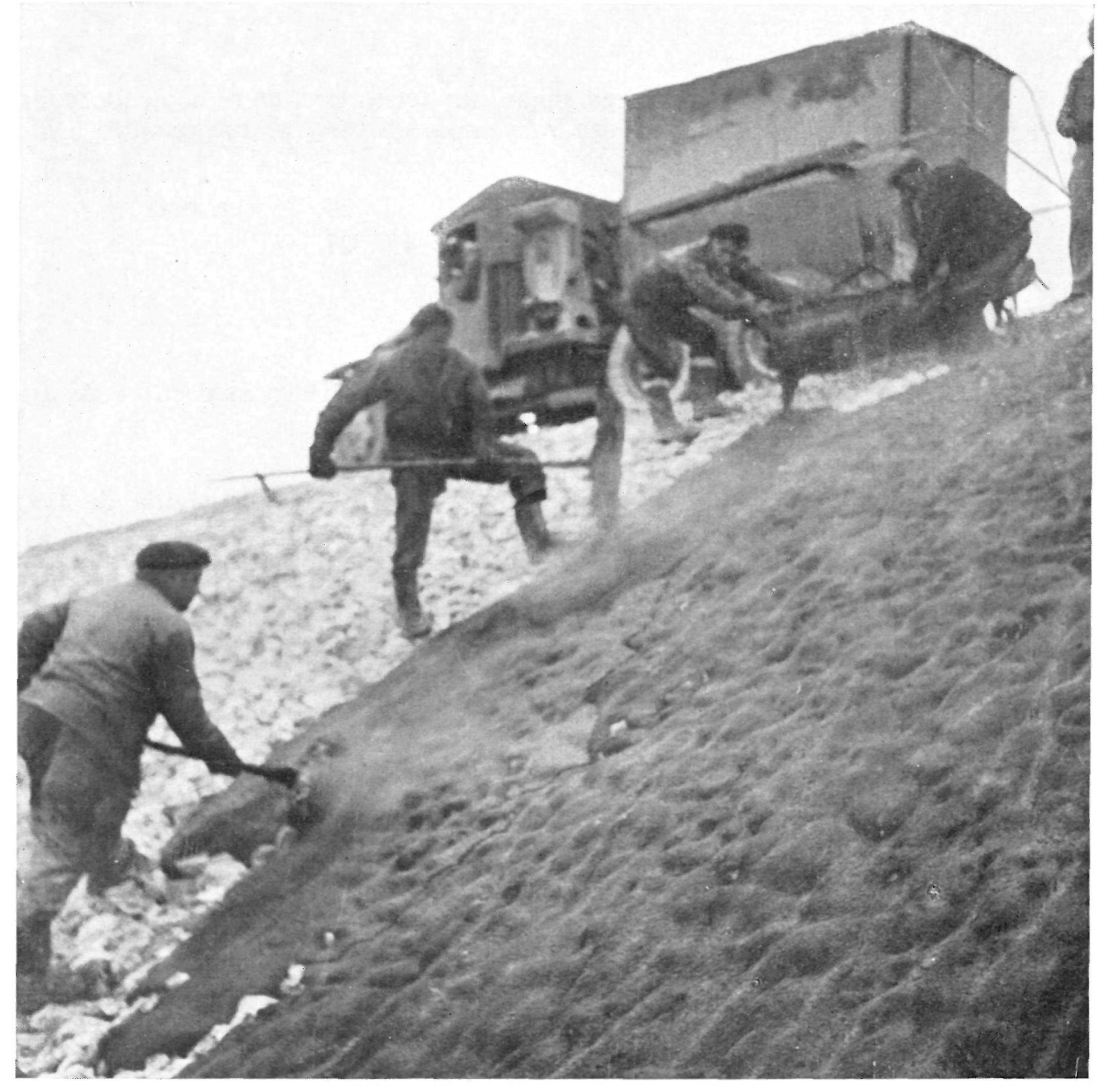

Fotos: SHELL- BERRE, Foto L SCIARLI y Agencia fotográfica BASQUE

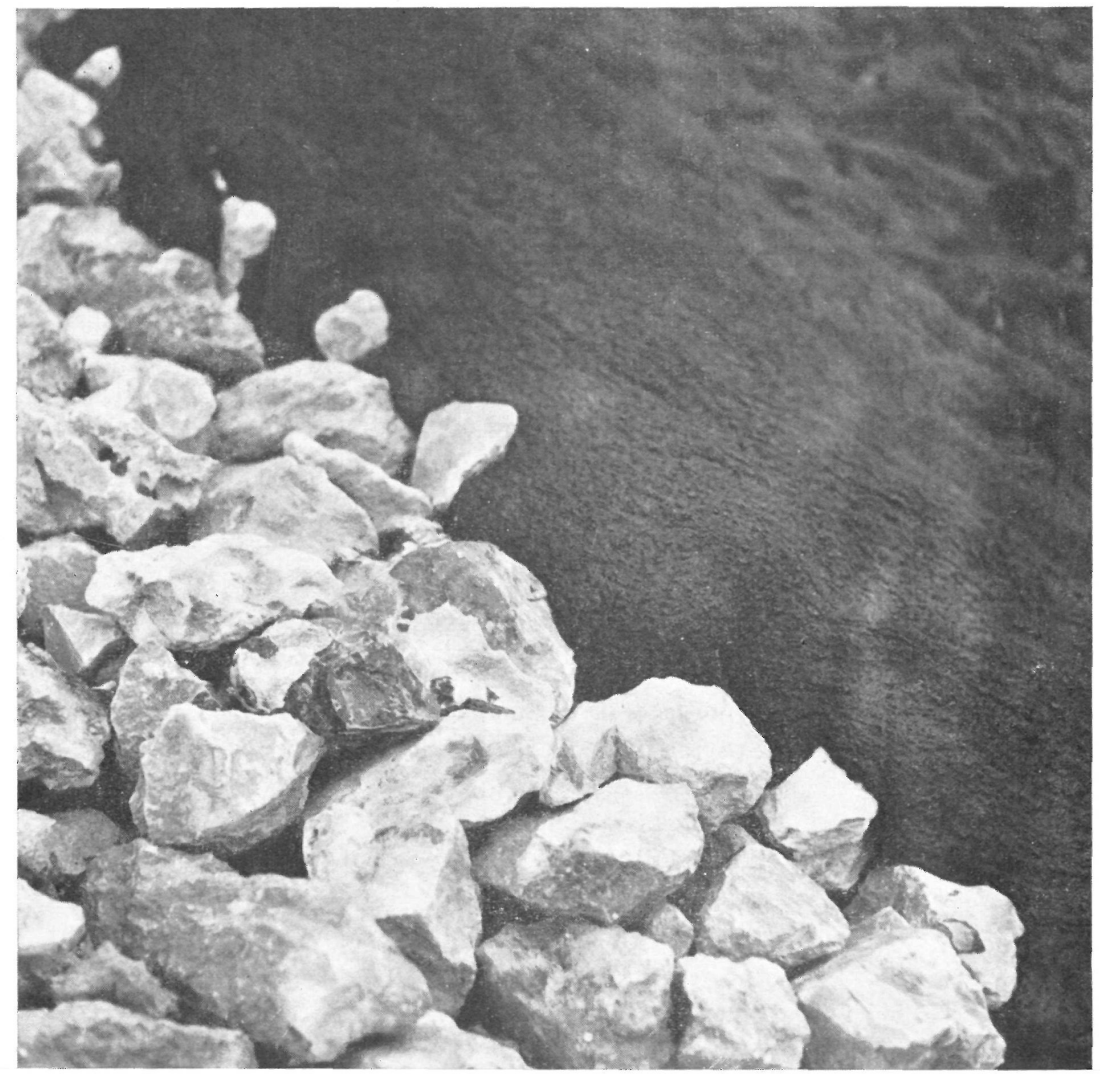

75 
0,10 $\mathrm{m}$, que comprende, en primer lugar, un lecho de $0,06 \mathrm{~m}$ colocado sobre un soporte nivelado (aluvio nes procedentes del Rin), y una segunda capa, de $0,04 \mathrm{~m}$, que recubre a la primera, y preparada así:

$\begin{array}{lrl}\text { Gravilla rodada } 2,5 / 10 & 50 \% \text { (en peso) } \\ \text { Arena semitriturada } 0 / 4 & 27 \% & \% \\ \text { Arena triturada } 0 / 4 & 17 \% & \% \\ \text { Filler calcáreo } & 4,5 \% & \$ \\ \text { Cal grasa } & 1,5 \% \quad » \\ \text { Betún } 60 / 70 & 6,9 \text { (partes en \% de áridos) }\end{array}$

En el apartadero de aguas arriba esta capa de 0,10 m está protegida de los choques de las barcazas por medio de dos capas suplementarias de $0,10 \mathrm{~m}$ en la orilla izquierda y otras tres análogas en la orilla derecha, de un hormigón bituminoso compacto cuya composición es la siguiente:

$\begin{array}{lcc}\text { Gravilla } 10 / 25 & 34,5 \% \text { (en peso) } \\ \text { Gravilla } 25 / 10 & 20 \% & \text { (20 } \\ \text { Arena semitriturada } 0 / 4 & 27 \% & \% \\ \text { Arena triturada } 0 / 4 & 17 \% & \\ \text { Cal grasa } & 1,5 \% \quad » \\ \text { Betún } 60 / 70 & 4,5 \text { (partes en \% de áridos) }\end{array}$

La diferencia de composición es evidente, en función del destino del recubrimiento.

Esta misma técnica se había empleado anteriormente para la construcción de apartaderos aguas arriba de los saltos de EDF de Rhinau y de Marckolsheim, y la repetición del método obedece a las observaciones favorables realizadas sobre su comportamiento actual.

Otros casos interesantes son el del Canal del Norte, que une, sobre un trazado de $95 \mathrm{~km}$, el canal de la Sensée en Arleux y el canal secundario del Oise, en Noyon.

El gálibo permite la circulación de chalanas de $350 \mathrm{t}$ con un calado de $2,2 \mathrm{~m}$ y convoyes remolcados formados por dos barcazas de $38,5 \mathrm{~m}$ de eslora, que pueden transportar casi 700 toneladas.

La sección tipo del canal mide $22 \mathrm{~m}$ de anchura en su altura máxima, con un fondo de $3 \mathrm{~m}$ y una pendiente de ribazos de $3 / 2$.

La estanquidad era tanto más necesaria cuanto que la alimentación de agua del canal estaba totalmente asegurada por bombeo.

En todos los sitios donde los terrenos no son suficientemente impermeables y donde la capa freática está situada a una cota inferior a la del nivel del agua, el canal está dotado de revestimientos de estanquidad de ribazos y de orillas. Los revestimientos suponen, de este modo, una longitud acumulada de $18.200 \mathrm{~m}$ en tres tramos, al atravesar los cuales el terreno es generalmente heterogéneo (capas de arena y de arcilla superpuestas) con pequeñas capas de agua encerradas, capaces de provocar subpresiones.

Se ha preparado después un drenaje formado por una capa de hormigón de cemento pobre, poroso, de $0,10 \mathrm{~m}$ de espesor, sobre la cual se ha colocado una capa de 0,06 $\mathrm{m}$ de hormigón bituminoso estanco.

Una capa de agarre $\left(0,5 \mathrm{~kg}\right.$ de emulsión catiónica $\left./ \mathrm{m}^{2}\right)$ ha sido extendida sobre la capa de drenaje, con la siguiente dosificación del hormigón bituminoso estanco:

Gravilla $8 / 10$ de piedra dura Gravilla $3 / 8$ de piedra dura Arena de machaqueo $0 / 3$

Arena eólica $0 / 1$

Filler calcáreo

Betún 60/70

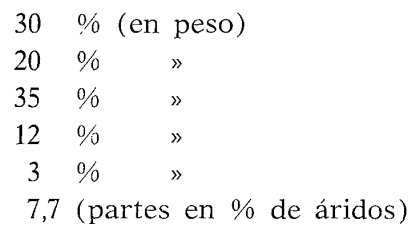

$30 \%$ (en peso)

$20 \%$ »

7,7 (partes en \% de áridos) 
La puesta en obra se efectuó por medio de una máquina repartidora, que se desplazaba sobre raíles colocados sobre el ribazo y la orilla superior del canal, raíles que servían también para transportar todos los materiales de la obra.

Una apisonadora especial de dos rodillos de 0,7 t ha permitido obtener una compacidad de 96,5 a 99,5\%, con coeficientes de permeabilidad del orden de $10^{-7} \mathrm{~cm} /$ segundo.

Para el revestimiento de la parte superior de las orillas se ha construido in situ una membrana bituminosa.

Después de arreglar cuidadosamente esta parte superior de las orillas con una capa de casi 0,005 m y eventual aportación de arena, se hizo una primera repartición de $4 \mathrm{~kg} / \mathrm{m}^{2}$ de betún, seguida de la colocación de una tela de vidrio con malla de $0,001 \mathrm{~m}$ y una resistencia a tracción de $11 \mathrm{~kg} / \mathrm{cm}^{2}$. Después se procedió a una segunda repartición de betún $\left(4 \mathrm{~kg} / \mathrm{m}^{2}\right)$, seguida de 30 litros de gravilla $5 / 25$ por metro cuadrado. La malla de fibra de vidrio aporta la resistencia a tracción necesaria para evitar el riesgo de rotura de la membrana, mientras que las gravillas confieren el peso y la protección mecánica.

La vía navegable, que tiene un gran tráfico, que procede de los puertos de Dunkerque y Calais, con destino a los grandes centros industriales de Lille y Valenciennes, y con miras a asegurar el enlace con la cuenca hullera del Norte y la zona siderúrgica de Escaut, permite la circulación de convoyes remolcados de $3.000 \mathrm{t}$, allí donde las chalanas no exceden de las 300 toneladas.

La distancia Dunkerque-Valenciennes es de $178 \mathrm{~km}$ siguiendo el trazado fluvial.

El gálibo primitivo era demasiado estrecho y estaba demasiado encerrado en la aglomeración urbana de Dunkerque para permitir una buena instalación moderna. Un nuevo trazado rodea el complejo siderúrgico y desemboca en el puerto, hacia el extremo occidental del dique marítimo.

Los taludes de esta desviación han sido protegidos con una capa de drenaje de $0,20 \mathrm{~m}$ de materiales calizos, que a su vez ha recibido otra capa de $0,10 \mathrm{~m}$ de revestimiento bituminoso.

Una de las secciones, comprendida entre Meurchin y Pont-à-Vendin, en el Canal de la Alta-Deule, ha sido ensanchada, con los taludes recubiertos a base de revestimientos bituminosos. Sobre una pendiente de $3 / 2$, una capa de revestimientos «abiertos» se ha aplicado sobre cimientos a base de escoria de horno alto, o de caliza, de unos 0,10 metros.

La puesta en obra de los revestimientos bituminosos se realizó en seco, al abrigo de un merlón destruido en el momento en que empezó a circular el agua.

En la región de Douai ha sido necesario proceder al ensanche de la vía navegable anteriormente existente para ampliar su gálibo.

El agrietamiento de los ribazos podía ocasionar movimientos de tierras y el revestimiento debía, por tanto, responder a imperativos de estabilidad y flexibilidad. Por este motivo, se eligió un revestimiento por penetración (penetración de un mástique bituminoso en un revestimiento de piedra más o menos suelta) en una longitud de 7.350 metros.

Dicho revestimiento consta de un lecho de arena de $0,04 \mathrm{~m}$ que sirve de base a los morrillos de $0,20 \mathrm{~m}$, rellenados con el mástique bituminoso vertido en caliente y preparado así:

$\begin{array}{lrl}\text { Arena de machaqueo } 0 / 3 & 47,5 \% \text { (en peso) } \\ \text { Arena del Rin clasificada } 0 / 6 & 47,5 \% & \\ \text { Filler calcáreo } & 5 \% & \\ \text { Betún } 60 / 70 & 19 \quad \text { (partes en } \% \text { de áridos) }\end{array}$

Dado que la organización del enlace Rin-Ródano debía permitir que convoyes remolcados de $3.200 \mathrm{t}$ fueran en tres días desde Lyon a Estrasburgo, ha sido obligada la reparación y ensanchamiento del canal de Huningue, primitivamente concebido para unir Bale y Mulhouse.

El ensanchamiento del gálibo suponía el desplazamiento del ribazo sur y el rebaje de las orillas. 
La primera sección ha recibido un revestimiento bituminoso, elegido en función de su buen comportamiento ante las heladas, de su flexibilidad y de su resistencia a los choques debidos al movimiento de los bloques de hielo.

Se han obtenido experimentalmente resultados satisfactorios $\mathrm{y}$, por consiguiente, la estanquidad de la sección Niffer-Mulhouse ha sido asegurada por la colocación de los revestimientos siguientes:

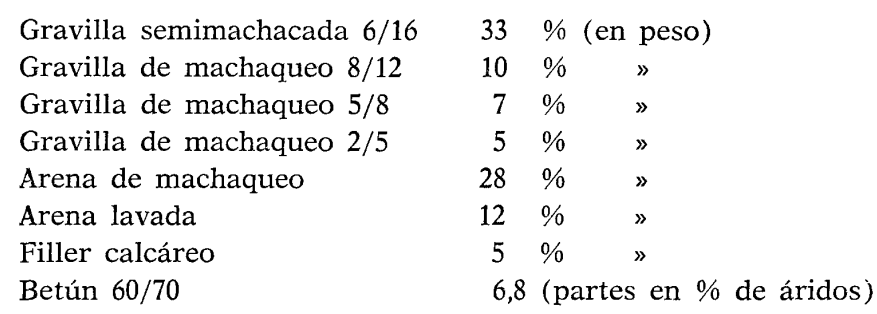

Para la ejecución de trabajos en el mar, el betún se pone en obra bajo formas diferentes: revestimientos, mástiques y capas envolventes. Así se hizo para el dique de Berck, en Hode sur Mer, en las costas de Bretaña y del Atlántico (Punta de Grave, muelle en la embocadura del Adour, en Boucau, etc.).

La ampliación del puerto de Dunkerque ha originado la creación de un dique de $6 \mathrm{~km}$ de longitud, protegiendo los terrenos ganados al mar, para la construcción de un complejo siderúrgico, de una central térmica y la ampliación de una refinería de petróleo.

Una nueva dársena marítima ha sido también construida sobre una superficie de $2.500 \times 200$ metros.

La protección del muelle y de las riberas de la dársena se ha asegurado por revestimiento bituminoso, según una técnica cuyo empleo se desarrolla también en Holanda para la realización del Plan Delta.

Cerca de $350.000 \mathrm{t}$ de hormigón bituminoso y más de $20.000 \mathrm{t}$ de mástique bituminoso han necesitado más de $25.000 \mathrm{t}$ de betún en total.

La primera fase de trabajo se terminó antes de 1966, y otra, después.

Se notará una evolución en la composición del hormigón bituminoso, después de la primera experiencia:

\begin{tabular}{|c|c|c|c|c|}
\hline \multicolumn{2}{|r|}{ ANTES DE 1966} & \multicolumn{3}{|c|}{ DESPUES DE 1966} \\
\hline Caliza 5/15 & $45 \%$ (en peso) & Caliza $8 / 16$ & $40 \%$ & n peso) \\
\hline Caliza $0 / 5$ & $30 \% \quad »$ & Caliza $0 / 3$ & $35 \%$ & $»$ \\
\hline Arena de dunas & $20 \%$ & Arena de dunas & $23,5 \%$ & $»$ \\
\hline Filler calcáreo & $5 \% \quad »$ & Filler calcáreo & $1,5 \%$ & $»$ \\
\hline Betún $60 / 70$ & 6,5 (partes en \% de áridos) & Betún $60 / 70$ & $7,2(\mathrm{pr}$ & tes en $\%$ \\
\hline
\end{tabular}

Para el mástique bituminoso, la fórmula adoptada fue:

$\begin{array}{ll}\text { Arena caliza de machaqueo } 0 / 3 & 47 \% \text { (en peso) } \\ \text { Arena de dunas } & 40 \% " \\ \text { Filler calcáreo } & 13 \% \\ \text { Betún } 60 / 70 & 20 \text { (partes en } \% \text { de áridos) }\end{array}$

Las razones que aseguran el éxito del betún para los trabajos en el mar resultan de la simplicidad de su puesta en obra, de su resistencia a los esfuerzos dinámicos del agua, de su insensibilidad a la corrosión salina y de su fraguado inmediato, sea bajo el agua, sea en seco, con marea baja.

Cuando sube la marea, el betún que está solidificado no es afectado por el cambio brusco de temperatura.

Se puede aconsejar, en la mayor parte de los casos, el método de fijación de rocas bajo el agua por penetración de mástique bituminoso vertido en caliente.

Traducido y adaptado por A. Barbero. 


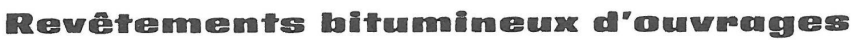 hegd ofruliques}

Georges Vié, ingénieur des mines

Il s'agit ici de l'emploi adéquat des bitumes pour la solution de bon nombre de problèmes posés par certains ouvrages hydrauliques, tels que les canaux, protection de quais, digues, etc.

Grâce à leur grande souplesse et à leur imperméabilité, les bitumes permettent la construction, sans joint, d'ouvrages capables de résister à l'érosion et aux chocs. Il faut aussí tenir compte de la facilité et de la rapidité de leur mise en place, qui favorise et généralise de plus en plus leur emploi.

\section{Bifumminous covering im thydrumbic works}

Georges Vié, mining engineer

This refers to the suitable use of bitumens in many problems that arise in some hydraulic projects, such as water supply canals, wharf protection, dykes, etc.

Due to its high flexibility and waterproofing capacity, it facilitates the construction of works that can resist erosion and collisions, without need to provide dilation joints. Account should also be taken of ease to fit it in place at the working site, which is an additional factor favouring its increasing use.

\section{Bituminäse Auskleidumg vom thydrumbischem Arbeitrem}

Georges Vié, Bergbauingenieur

Hier wird die angemessene Verwendung von Bitumen zur Lösung zahlreicher Probleme im Zusammenhang mit hydraulischen Arbeiten, wie z.B. der Versorgung von Kanälen, dem Schutz von Molen und Deichen, usw. beschrieben.

Aufgrund ihrer Biegungsfähigkeit und Undurchlässigkeit ermöglichen sie Bauten, die erosions: und stossicher sind ohne Fugen. Ausserdem muss ihre leichte und schnelle Errichtung beachtet werden. All dies beguinstigt und verbreitet ihre Anwendung immer mehr. 